\title{
Algal Lipid Extraction and Upgrading to Hydrocarbons Technology Pathway
}

Ryan Davis and Mary Biddy National Renewable Energy Laboratory

Susanne Jones

Pacific Northwest National Laboratory

NREL is a national laboratory of the U.S. Department of Energy, Office of Energy Efficiency \& Renewable Energy, operated by the Alliance for Sustainable Energy, LLC, under contract DE-AC36-08G028308.

Pacific Northwest National Laboratory is operated by Battelle for the United States Department of Energy under contract DE-AC05-76RL01830.

Technical Report

NREL/TP-5100-58049

PNNL-22315

March 2013

Prepared for the U.S. Department of Energy Bioenergy Technologies Office 


\section{Algal Lipid Extraction and Upgrading to Hydrocarbons Technology Pathway}

Ryan Davis and Mary Biddy National Renewable Energy Laboratory

Susanne Jones

Pacific Northwest National Laboratory

NREL is a national laboratory of the U.S. Department of Energy, Office of Energy Efficiency \& Renewable Energy, operated by the Alliance for Sustainable Energy, LLC, under contract DE-AC36-08G028308.

Pacific Northwest National Laboratory is operated by Battelle for the United States Department of Energy under contract DE-AC05-76RL01830.

Technical Report

NREL/TP-5100-58049

PNNL-22315

March 2013

Prepared for the U.S. Department of Energy Bioenergy Technologies Office

National Renewable Energy Laboratory 15013 Denver West Parkway Golden, Colorado 80401 303-275-3000 • www.nrel.gov
Pacific Northwest National Laboratory P.O. Box 999

Richland, WA 99352

1-888-375-7665 • www.pnl.gov 


\section{NOTICE}

This report was prepared as an account of work sponsored by an agency of the United States government. Neither the United States government nor any agency thereof, nor the Alliance for Sustainable Energy, LLC, nor Battelle Memorial Institute, nor any of their employees, makes any warranty, express or implied, or assumes any legal liability or responsibility for the accuracy, completeness, or usefulness of any information, apparatus, product, or process disclosed, or represents that its use would not infringe privately owned rights. Reference herein to any specific commercial product, process, or service by trade name, trademark, manufacturer, or otherwise does not necessarily constitute or imply its endorsement, recommendation, or favoring by the United States government or any agency thereof. The views and opinions of authors expressed herein do not necessarily state or reflect those of the United States government or any agency thereof, or the Alliance for Sustainable Energy, LLC, or Battelle Memorial Institute.

Available electronically at http://www.osti.gov/bridge

Available for a processing fee to U.S. Department of Energy and its contractors, in paper, from:

U.S. Department of Energy

Office of Scientific and Technical Information

P.O. Box 62

Oak Ridge, TN 37831-0062

phone: 865.576 .8401

fax: 865.576.5728

email: mailto:reports@adonis.osti.gov

Available for sale to the public, in paper, from:

U.S. Department of Commerce

National Technical Information Service

5285 Port Royal Road

Springfield, VA 22161

phone: 800.553 .6847

fax: 703.605.6900

email: orders@ntis.fedworld.gov

online ordering: http://www.ntis.gov/help/ordermethods.aspx

Printed on paper containing at least $50 \%$ wastepaper, including $10 \%$ post consumer waste. 


\section{Algal Lipid Extraction and Upgrading to Hydrocarbons}

\section{Developing Pathway Cases to Understand the Cost of Converting Biomass to Hydrocarbon Fuels}

In support of the Bioenergy Technologies Office, the National Renewable Energy Laboratory (NREL) and the Pacific Northwest National Laboratory (PNNL) are undertaking studies of biomass conversion technologies to identify barriers and target research toward reducing conversion costs.

Process designs and preliminary economic estimates for each of these pathway cases were developed using rigorous modeling tools (Aspen Plus and Chemcad). These analyses incorporated the best information available at the time of development, including data from recent pilot- and bench-scale demonstrations, collaborative industrial and academic partners, and published literature and patents. The economic results of these analyses are in the process of further refinement and will be published in FY13 and FY14 design reports. This report summarizes the preliminary technical data used for the models and identified data gaps.

This technology pathway case investigates the cultivation of algal biomass followed by further lipid extraction and upgrading to hydrocarbon biofuels. Technical barriers and key research needs have been assessed in order for the algal lipid extraction and upgrading pathway to be competitive with petroleum-derived gasoline-, diesel-, and jet-range hydrocarbon blendstocks.

\section{Process Block Diagram}

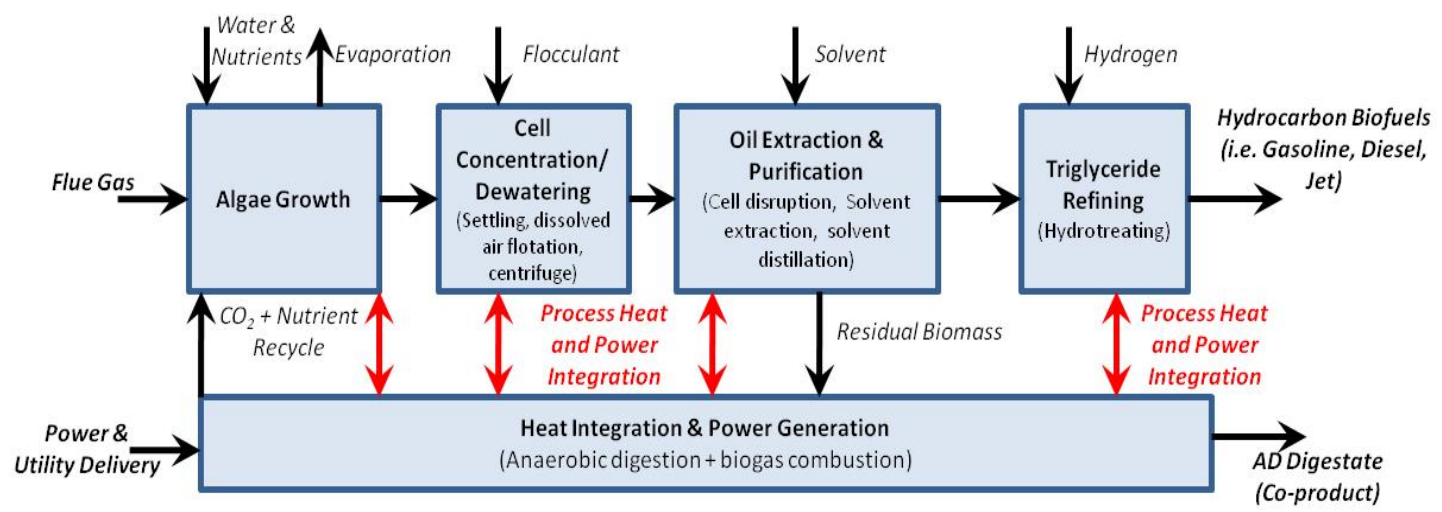

\section{Key Highlights}

- Microalgae grown via autotrophic pathways have the potential to make sizeable contributions to renewable fuel mandates, particularly due to their rapid growth rates and other favorable cultivation characteristics relative to terrestrial biomass feedstocks.

- Some microalgae accumulate moderate levels of triglyceride (TAG) components for subsequent targeted extraction and conversion into diesel-range fuel, and the raw algal oil intermediate is expected to require relatively mild upgrading (hydrotreating) to finished fuels at marginal cost. 
- Algal biomass can be tailored to produce specific components for fuel and/or product markets (potential for high-value co-products).

- For the algal lipid extraction and upgrading pathway, the overall economics for hydrocarbon biofuels are more strongly influenced by improvements in extractable lipid content than productivity.

- Important research needs for this pathway include enhancing algal oil productivity on a sustained basis, improving the algae dewatering and lipid extraction techniques and efficiencies at large scale, and characterizing the extracted algal oil and subsequent upgrading costs.

\section{Process Design Details}

For purposes of the scoping analysis exercise, the current algal lipid extraction and upgrading (ALU) case described here is based on the process and cost assumptions detailed in the algae harmonization report released jointly between NREL, Argonne National Laboratory, and PNNL in June 2012 (Davis et al. 2012).

Cultivation: Autotrophic microalgae can be cultivated using either open pond or closed photobioreactor (PBR) configurations. During early stages of algal TEA modeling, NREL investigated process and cost trade-offs for cultivation in either open raceway ponds or in tubular PBR systems, and found that PBRs are expected to cost at least twice as much as open pond cultivation on a per-gallon selling price basis, despite several key advantages of the PBR system (Davis et al. 2011). The harmonization report focused exclusively on open pond cultivation, with the majority of pond design and cost assumptions based on a recent report by Lundquist et al., including large 4-hectare (ha) ponds with paddle-wheel mixing consuming an average of $2.0 \mathrm{~kW}$ per hectare (Lundquist et al. 2010) at a total installed cost of $\$ 34,000 /$ ha (2009-dollars). On top of this cost, plastic liners were conservatively added to allow for more universal applicability for open pond systems where local soil characteristics may not be optimal from a drainage/ percolation or structural integrity standpoint, costed based on literature information (Stone 1999). The installed price for pond liners is expected to make overall economics considerably more challenging. To ultimately achieve economic viability, proper site location and system design will be important to optimize such that a need for plastic pond liners is greatly reduced or eliminated, thus mitigating this cost bottleneck. Both the pond and liner costs are two of the most critical cost elements of the ALU pathway, given the very large surface area assumed in the present models of 10,000 acres of total pond area.

For nutrient costing purposes, the algal biomass composition was set at a $\mathrm{C}: \mathrm{N}: \mathrm{P}$ molar ratio of 175:21:1 according to the medium-lipid scenario presented in Williams and Laurens (2010), with nitrogen and phosphorous demands met using ammonia and diammonium phosphate respectively, priced at fertilizer prices according to the USDA. A large fraction of the nutrients are recycled from the downstream anaerobic digestion step, thus resulting in considerable savings in makeup nutrient costs. These savings are specific to the use of anaerobic digestion in the model and would be lost if switching to a different co-product pathway (animal feed, etc.). $\mathrm{CO}_{2}$ requirements are met by transporting flue gas at low pressure in a pipeline system branching out from a power plant or other flue gas source, transported for one mile from source to pond facilities. 
While ponds and liners are key cost drivers from an engineering standpoint, the economics are also heavily dependent on overall process yields, which are driven by both algal growth rate (productivity) and lipid content. Large discrepancies exist in literature around today's state of technology for these parameters, particularly for productivity; for example, L. Brennan reports observed productivities ranging from 11-69 $\mathrm{g} / \mathrm{m}^{2} /$ day (Brennan and Owende 2010), while M. Griffiths presents a review for outdoor cultures ranging from 11-48 g/m $/ \mathrm{m}^{2} /$ day (Griffiths and Harrison 2009). Even larger ranges are reported in other studies (Sun et al. 2011; Quinn et al. 2012). However, a key element that is largely lacking from most studies is the governing conditions under which the data were gathered (with many studies conducted under conditions optimized for laboratory experiments), with necessary data particularly lacking for large-scale, outdoor, year-round operation. As noted in the harmonization report, the baseline values estimated to represent today's performance at large scale are set at a year-average algal productivity of $13 \mathrm{~g} / \mathrm{m}^{2} /$ day and $25 \mathrm{wt} \%$ lipid content (Davis et al. 2012), or near 1,300 gal/acre/year of algal oil. To reduce fuel selling price to a competitive target, there is room to improve these parameters to a range of 5,000-6,000 gal/acre/year, which is a target generally agreed to be realistically achievable (ABO 2011), and much less than the theoretical photosynthetic maximum of 38,000 gal/acre/year (Weyer et al. 2010). Target projections exceeding 6,000 gal/acre/year are also stipulated in literature, sometimes by drastically higher amounts, but are generally not based on real-world insight.

Concentration/dewatering: Following cultivation, algal cells are assumed to be harvested from the ponds at a steady-state concentration of $0.5 \mathrm{~g} / \mathrm{L}$ and must be concentrated for subsequent extraction and processing. The dewatering steps consist of settling (auto-flocculation), dissolved air flotation (DAF) assisted by adding a flocculant, and centrifugation. Although the primary settling step is the simplest of the three dewatering operations, it incurs the majority of the cost for the operations given the very low starting concentration and thus very high total volume throughput. The material achieves a concentration of $10 \mathrm{~g} / \mathrm{L}(1 \mathrm{wt} \%$ solids $)$ after primary settling, $60 \mathrm{~g} / \mathrm{L}$ (6 wt\%) after DAF using an organic polymer flocculant (chitosan), and $200 \mathrm{~g} / \mathrm{L}$ $(20 \mathrm{wt} \%)$ after centrifugation. While the use and efficacy of these operations is supported in literature with similar performance as modeled here (Uduman et al. 2010), they are based on somewhat antiquated techniques for wastewater processing, and may leave room for more costeffective dewatering methods with the use of alternative technologies currently being investigated for algal processing. While operational data for such alternatives are largely lacking in the public domain as of yet, reducing capital and operating costs for dewatering relative to the baseline operations employed here will be another important metric to achieving economic viability.

Extraction: Following cell concentration to $200 \mathrm{~g} / \mathrm{L}$, the algal material is sent to a wet extraction process. As described in the harmonization report, the process consists of cell disruption using high-pressure homogenization, followed by solvent extraction with hexane at a solvent ratio of $5: 1 \mathrm{~kg}$ solvent per kg dry biomass. The material is then separated into a light phase (primarily extracted oil and solvent) and a heavy phase (water, spent algal residue, and oil/solvent carryover) in a disk stack centrifuge. The solvent is stripped from the oil and recycled using distillation, leaving a relatively pure raw oil stream. The heavy phase containing the algal residue is sent to anaerobic digestion. 
The extraction step carries a relatively high degree of uncertainty in terms of overall process performance and efficiency assumptions. This is primarily due to the fact that pertinent literature data are scarce, and the majority of data that are available are based on bench-scale experiments that dry the material to very low moisture levels ( $<5 \mathrm{wt} \%$ moisture) and use solvent combinations that would be commercially infeasible. The process assumptions used here for wet extraction are based on the best available data from literature (e.g., Nagle and Lemke 1989) and industry feedback. As noted in the harmonization report, the algal oil is currently assumed to be essentially $100 \%$ triglycerides whose extraction efficiency meets the assumed targets and whose quality meets standards for catalytic upgrading. It is recognized that in reality, the oil will also contain components such as polar lipids, hydrophobic proteins, and pigments, which may not extract as readily, and which may reduce catalyst lifetime if they were to be extracted and sent to hydrotreating (such components are not included in the assumed lipid content values for extraction modeling purposes). It will be important moving forward to work with researchers to integrate updated extraction data as they become available into the models, as well as to better characterize the algal oil to understand implications on subsequent cleanup and/or refining steps.

Spent biomass utilization (anaerobic digestion): The heavy phase leaving the extraction step contains water, spent (lipid-extracted) algal residue, whole (un-extracted) cells, and a small amount of oil and solvent due to carryover losses during phase separation. This stream is sent to anaerobic digestion (AD), which breaks down the material into a biogas stream, a nutrient-rich liquid effluent, and a high-solids digestate (sludge) stream. The biogas is burned in a gas turbine for heat and power generation, and the flue gas is recycled back to the ponds to minimize fresh $\mathrm{CO}_{2}$ demands. The nutrient-rich supernatant is recycled to the ponds and reduces fresh nitrogen demand by roughly $75 \%$ and phosphorous demand by roughly $50 \%$. The digestate material is sold as a fertilizer co-product at a rate of \$500/tonne of nitrogen (Lundquist et al. 2010), assuming that $40 \%$ of the total nitrogen is bioavailable. The AD performance (e.g., biogas yields, nitrogen and phosphorous fixation, residence time) was set based on literature studies for digestion of algal biomass and algal residues (Davis et al. 2012), though these figures are being validated by work done at NREL and Washington State University. Cost was scaled from the AD unit utilized in the NREL 2011 biochemical ethanol design report (Humbird et al. 2011).

In the ALU pathway, $50 \%-75 \%$ of the "feedstock" (algal biomass) remains unutilized for conversion to fuels. This results in a large amount of material available for utilization as a coproduct, thus the choice for the co-product pathway can potentially be a very large economic and sustainability driver for the process. A number of options exist for the spent algal residue, including AD, selling as animal or fish feed, conversion into additional fuel products, or highvalue food/nutraceutical applications (e.g., $\omega-3$ fatty acids). For the models described in the harmonization report, the decision was made to use $\mathrm{AD}$, given the maturity of the technology, large-scale applicability, and important sustainability/life cycle assessment (LCA) implications associated with nutrient recovery and power generation.

Product upgrading: After separation from the hexane solvent, the extracted raw algal oil is sent to a central hydrotreating unit. To ensure sufficient scale is achieved for the hydrotreater, the harmonization model assumes that extracted oil from four pond facilities $(10,000$ acres of ponds each) feeds into a single upgrading facility. Given the relatively early state of the model and the focus placed thus far on the front end through raw oil production, the assumptions utilized for the hydrotreating step and specific algal oil characteristics are currently somewhat less detailed. The 
models currently assume that the stated "lipid content" is essentially $100 \%$ triglyceride, and thus ignores impurities that may be present such as phospholipids and nitrogen-containing impurities that could require additional cleanup. Additionally, hydrotreating process specifications such as hydrogen demand, pressure, and temperature are based on a compilation of literature studies for hydrotreating vegetable oils (primarily Marker et al. 2005), and thus are currently independent of the specific oil characteristics such as degree of saturation. The cost for upgrading is based on a scaling-factor approach for a general hydrotreating plant (in general, the hydrotreating cost is not currently envisioned to present a large economic hurdle). The upgrading process and cost assumptions utilize a product yield of $93 \mathrm{vol} \%$ and $3.5 \mathrm{vol} \%$ for diesel and gasoline range blendstocks, respectively.

Utilities: While the ALU model does not require extensive utilities, the utilities that are required are currently assumed to be purchased at published utility prices. This includes cooling water and steam (if insufficient heat is available from biogas combustion) (Seider et al. 2004).

\section{Data Gaps, Uncertainties, and Research Needs}

While the ALU pathway is based on the best available information from literature and detailed modeling as described in the harmonization report, it is generally lacking on first-hand data from program-funded research, and thus is inherently still a largely theoretical model. Nevertheless, all process assumptions have been vetted with industry and research stakeholders in numerous forums (namely peer-reviewed publications and the harmonization workshop), which adds an important degree of credibility to the modeling baseline. Additionally, the cost assumptions are largely derived from literature, engineering cost factors, and approximate vendor quotations.

The goal of this pathway is to reach a minimum fuel selling price of $\$ 3 /$ gallon of gasoline equivalent. To reach this targeted product price, the key bottlenecks, uncertainties, and areas for further development are summarized as follows:

- Validate algae growth and oil productivity rates based on data from large scale demonstrations. Previous work has demonstrated a strong economic sensitivity to lipid content and algal growth rate. Much of the existing data is based on literature values in controlled environments. It will be important to incorporate first-hand operational data on large-scale, outdoor, year-round operation to validate the assumptions and projections for these metrics.

- Confirm design requirement of pond liners. The costs for liners in algae cultivation exhibit the largest single-unit impact on overall economics and there is a great deal of uncertainty on their requirement. In reality, their use will depend on local soil characteristics, algal strain employed, and governing regulatory policies.

- Reduce cost and increase efficiency of algae dewatering and concentration steps. While the performance for dewatering operations is supported to a degree in literature (for operations utilizing wastewater dewatering technologies), such operations leave room for further cost reduction if more cost-effective alternatives can be developed and proven at large scale. 
- Reduce cost and increase efficiency of lipid extraction. There is a dearth of literature data on specific process conditions and performance for algal lipid extraction in general, and particularly for wet extraction at $10 \mathrm{wt} \%-20 \mathrm{wt} \%$ solids. While the model currently assumes that the algal oil is entirely TAG components, non-TAG constituents such as polar lipids or free fatty acids may not extract as readily (although some such components may not necessarily be desirable either). Thus it will be important to incorporate experimental data into the model to validate the process and resulting efficiency assumed here, and to begin understanding specifically what alternative operations will be able to achieve cost reductions necessary for economic viability.

- Demonstrate upgrading of algal oil. Better characterization of the extracted algal oil will help in the design and understanding of more specific hydrotreating costs and associated potential for improvement. Opportunities exists for the design and optimization of catalysts tailored for algal oil upgrading.

- Confirm AD performance. The assumptions currently employed for the anaerobic digestion (AD) operation, specifically metrics of biogas yield and nutrient fixation in the recycle effluent, are based on a compilation of literature studies. Some of these data are either dated or present conflicting results, and require further analysis.

- Evaluate co-product opportunities. There are many co-product opportunities that have yet to be fully explored for economic and LCA trade-offs and should further be considered going forward. One scenario considered by a number of literature studies and " 1 st of a kind" commercialization models utilizes high-value food or nutraceutical coproduct components to improve overall economics. These co-products, however, could quickly flood any such market at the large scale associated with fuels. A more feasible alternative at large scale might be animal or fish feed, but future work should consider the impact on sustainability metrics given the loss of nutrient recycle and power generation.

\section{Summary and Next Steps}

This study assessed the processing of algal biomass conversion via lipid extraction followed by upgrading and finishing to gasoline-, diesel-, and jet-range hydrocarbon blendstocks. This techno-economic analysis was performed to identify technology gaps, uncertainties, and research needed to achieve a minimum fuel selling price of $\$ 3 /$ gallon of gasoline equivalent. A design case detailing this pathway will be developed by the end of FY14.

\section{References}

Algal Biomass Organization (ABO). (October 2011). "Plenary Session: An Update on the Global Consortia." Presented at the 2011 Algae Biomass Summit (ABS).

Brennan, L.; Owende, P. (2010). "Biofuels from Microalgae - A Review of Technologies for Production, Processing, and Extractions of Biofuels and Co-Products." Renewable and Sustainable Energy Reviews (14); pp. 557-577.

Davis, R.; Aden, A.; Pienkos, P.T. (2011). "Techno-Economic Analysis of Autotrophic Microalgae for Fuel Production.” Applied Energy (88); pp. 3524-3531. 
Davis, R.; Fishman, D.; Frank, E.D.; Wigmosta, M.S.; Aden, A.; Coleman, A.A.; Pienkos, P.T.; Skaggs, R.J.; Venteris, E.R.; Wang, M.Q. (June 2012). Renewable Diesel from Algal Lipids: An Integrated Baseline for Cost, Emissions, and Resource Potential from a Harmonized Model. ANL/ESD/12-4; NREL/TP-5100-55431; PNNL-21437. Argonne, IL: Argonne National Laboratory; Golden, CO: National Renewable Energy Laboratory; Richland, WA: Pacific Northwest National Laboratory. http://www.nrel.gov/docs/fy12osti/55431.pdf.

Griffiths, M.J.; Harrison, S.T.L. (2009). "Lipid Productivity as a Key Characteristic for Choosing Algal Species for Biodiesel Production.” Journal of Applied Phycology (21); pp. 493-507.

Humbird, D.; Davis, R.; Tao, L.; Kinchin, C.; Hsu, D.; Aden, A.; Schoen, P.; Lukas, J.; Olthof, B.; Worley, M.; Sexton, D.; Dudgeon, D. (May 2011). Process Design and Economics for Biochemical Conversion of Lignocellulosic Biomass to Ethanol Dilute-Acid Pretreatment and Enzymatic Hydrolysis of Corn Stover. NREL/TP-5100-47764. Golden, CO: National Renewable Energy Laboratory. http://www.nrel.gov/biomass/pdfs/47764.pdf.

Lundquist, T.J.; Woertz, I.C.; Quinn, N.W.T.; Benemann, J.R. (2010). A Realistic Technology and Engineering Assessment of Algae Biofuel Production. Berkeley, CA: Energy Biosciences Institute, University of California. http:/www.energybiosciencesinstitute.org/sites/default/files/media/AlgaeReportFINAL.pdf.

Marker, T.; Petri, J.; Kalnes, T.; McCall, M.; Mackowiak, D.; Jerosky, B.; Reagan, B.; Nemeth, L.; Krawczyk, M.; Czernik, S.; Elliott, D.; Shonnard, D. (2005). Opportunities for Biorenewables in Oil Refineries. Final Technical Report. Prepared by UOP LLC, Des Plaines, IL. Submitted to U.S. Department of Energy under DOE award number DE-FG36-05GO15085. http://www.osti.gov/bridge/servlets/purl/861458-Wv5uum/861458.pdf.

Nagle, N.; Lemke, P. (1989). "Microalgal Fuel Production Processes: Analysis of Lipid Extraction and Conversion Methods." Extract from Bollmeier, W.S. and Sprague, S. eds. Aquatic Species Program Annual Report. Golden, CO: Solar Energy Research Institute; pp. 157-161. http://www.nrel.gov/docs/legosti/old/3579.pdf.

Quinn, J.C.; Catton, K.B.; Johnson, S.; Bradley, T.H. (September 2012). "GIS Evaluation of Microalgae Productivity including Resource Assessment." Presented at the 2012 Algae Biomass Summit (ABS).

Seider, W.D.; Seader, J.D.; Lewin, D.R. (2004). Product and Process Design Principles. $2^{\text {nd }}$ edition. New York: John Wiley \& Sons, Inc.

Stone, N. (1999). Renovating Leaky Ponds. SRAC Publication No. 105. Stoneville, MS: Southern Regional Aquaculture Center. Accessed January 18, 2012: https://srac.tamu.edu/index.cfm/event/getFactSheet/whichfactsheet/6/.

Sun, A.; Davis, R.; Starbuck, M.; Ben-Amotz, A.; Pate, R.; Pienkos, P.T. (2011). "Comparative Cost Analysis of Algal Oil Production for Biofuels.” Energy (36); pp. 5169-5179. 
Uduman, N.; Qi, Y.; Danquah, M.K.; Forde, G.M.; Hoadley, A. (2010). "Dewatering of Microalgal Cultures: A Major Bottleneck to Algae-Based Fuels." Journal of Renewable and Sustainable Energy (2); pp. 1-15.

Weyer, K.M.; Bush, D.R.; Darzins, A.; Wilson, B.D. (2010). "Theoretical Maximum Algal Oil Production." Bioenergy Research (3); pp. 204-213.

Williams, P.; Laurens, L. (2010). "Microalgae as Biodiesel and Biomass Feedstocks: Review and Analysis of the Biochemistry, Energetics and Economics." Energy \& Environmental Science (3); pp. 554-590. 